\title{
Students' View of the Use of TELL (Technology Enhanced Language Learning) in Remote Teaching
}

\author{
Alfi Hidayatu Miqawati ${ }^{1, *}$ Fitri Wijayanti ${ }^{2}$, Adriadi Novawan ${ }^{3}$ \\ 1, 2, ${ }^{3}$ Language, Communication, and Tourism Department, Politeknik Negeri Jember, Indonesia \\ ${ }^{*}$ Corresponding author. Email: alfi_hidayatu@polije.ac.id
}

\begin{abstract}
Technology in language teaching has been one of the most pivotal aspects in English Language Teaching (ELT) for decades. Many studies reveal considerable benefits of utilizing ICT in the teaching and learning process, especially when conducting remote teaching. This study focuses on analyzing students' descriptions about their experiences in emergency remote teaching and the opportunities and challenges for learning granted due to the transition to emergency remote teaching. This study deployed a descriptive qualitative method that involved 72 students of Polytechnic Negeri Jember who have experienced remote teaching for more than a year. The data were collected by using an open-ended questionnaire. The questionnaires were distributed using Google Form. The results showed that the students were able to be more adaptive with any kinds of applications required by their lecturers and it encouraged them to explore more platforms to support their independent learning. They also mentioned that their knowledge and awareness of digital ethics also increase. However, boredom, short-term concentration, weariness, gadget compatibility become a serious thread for remote teaching to be successful. In short, remote teaching provides a positive impact and challenges for students. To minimize the thread, more TELL-based teaching models and strategies, such as flipped classrooms, cooperative learning, and project-based learning are suggested.
\end{abstract}

Keywords: TELL, Technology, Remote Teaching, View.

\section{INTRODUCTION}

The concept of online learning that has run for decades is identical to a well-planned program conducted over a certain period of time. It is intentionally designed to be delivered fully online and involves several weeks of planning and designing from the very beginning. Many online learning programs have been proven to be able to assist students to gain knowledge and skills though, some believe that it is not as effective as face-to-face learning. However, with the massive emergence of technology, the provision of better infrastructure, the effectiveness of online learning has improved, yet, the temptation to compare between online learning and face-to-face instruction is still great [1].

Learning does not always occur in a normal way where all required factors are supporting it. Crisis circumstances, such as pandemics, natural disasters, war, and others, make both face-to-face learning and online learning hardly possible to conduct. Thus, an implementation of another model of instruction, in this case, is imperative. An alternative delivery mode for such crisis circumstances is Emergency Remote Teaching (ERT), which serves only as a temporary shift of instructional delivery. It covers the implementation of fully remote teaching and the instruction will return to the previous format (face to face or blended) once the emergency has abated. In these circumstances, its main objective is not to re-create a robust educational ecosystem but rather to present temporary access to instruction and instructional supports which is quick to set up and is reliably feasible during an emergency [1].

ERT is pervasive and has been conducted worldwide in any level of study (elementary, secondary, and tertiary) in the pandemic. However, since the situation is unprecedented and the massive implementation was not well designed, many unique cases occur, and there lacks literature that specifically examines ERT practices in higher education [2\}. [3] conducted a study that examined students' experiences with the ERT in an academic university, however, the sample size was small and he suggested more studies about this topic should be conducted. Many other studies about ERT were 
conducted to explore its practices in different settings. [4] examined students' learning platform preferences when conducting ERT and found out that among many platforms, WhatsApp outnumbered the others. [5] mentioned that ERT plays a vital role since it can help to disrupt inequities of education during a crisis and proceed toward an educational justice vision. Other former studies also mostly focused on the analysis of the positive and negative aspects of the implementation of online learning, its impacts toward students' achievement, motivation, and engagement, advantages obtained, and challenges to face [6], [7], [8].

In English Language Teaching (ELT) context, technology plays a pivotal role, especially in the practice of ERT. When conducting ERT, the most possible direct interaction is virtual interaction which is supported by TELL (Technology Enhanced Language Learning). The most possible means to bridge the gap among students, teachers, and learning resources is technology [10]. Either computer, internet, or mobile (android) based, provides a special room for supporting learning and enhancing students' success in learning [11]. Moreover, with the support of the internet and various online and offline platforms, students can have more exposure to facilitate their ERT experience. In short, TELL and ERT are indispensable.

This current phenomenon is critical to examine. [9] stated that limited studies explore the experience of new ERT. In addition, not any study has revealed literature that evaluates the practice of ERT in a vocational higher education setting. Thus, as ERT can play a massive role to facilitate learning in crisis, there is a need to fill the gap in the literature related to ERT experiences in vocational higher education. In this sense, this study aims at analyzing students' descriptions about their experiences in emergency remote teaching and the opportunities and challenges for learning granted due to the transition to emergency remote teaching.

\section{METHOD}

This study deployed a descriptive qualitative method. 72 students of Politeknik Negeri Jember who have experienced remote teaching for more than a year participated in this study. The instrument used to collect the data was an open-ended questionnaire in the form of Google Form. The open-ended questions were chosen for it provides more ample information about the respondents' answers. The questions cover perceptions toward ERT experience in terms of their learning process, their social-emotional stance, and other technical supports. The data were collected three times (the same respondents) within three semesters (two semesters at the 2020/2021 academic year and one semester at the
2021/2022 academic year). The data obtained were then analyzed descriptively.

\section{RESULTS AND DISCUSSION}

The research questions of this study cover two points. The first is the students' description about their experiences in emergency remote teaching and the second is opportunities and challenges for learning presented due to the transition to ERT.

\subsection{Learning Experience}

First, as the data were collected in three different semesters, the students' responses were compelling. At the beginning of the pandemic (the first time the questionnaire was distributed), they mentioned that the implementation of ERT was minimum. They were lack of knowledge and experience in using synchronous platforms like Zoom, Google Meet, and U Meet Me. Internet connection, bandwidth, and internet data also bothered them since the teachers use different synchronous and asynchronous platforms. It also made them confused and need to install many applications. However, many of their devices were not compatible with the applications, and or their mobile memory did not allow more spaces for newly installed applications. Only one platform was used by all of the lecturers, the Learning Management System (LMS). Some lecturers were flexible with the task and deadline of submission while some gave too much workload to handle and provide a little feedback. The worst thing they experienced was that at particular times, they were only given materials to download without any explanation or media to help them gain understanding about the materials. This situation made them think that they did not obtain ample knowledge and skill.

However, their opinion changed as the second and third data collection were conducted. They mentioned that they were more prepared and able to get the flow of ERT practice and the use of technology to support their learning. They were also elated since the government granted them monthly internet data support and their lecturers started to implement more various classroom activities and strategies. The platforms that they mainly use in ERT were LMS, Zoom, and WhatsApp. Some lectures sometimes used Padlet, Quizzes, Canvas, but in small portions of the teaching and learning process. They were fruitful experiences for the students as they could learn more about technologies

In addition, the students also mentioned that they gained less in terms of language skills and competencies when using ERT compared to face-to-face instruction. They were also not able to manage their time appropriately and even, some others failed to mane their 
time since they got many distractions when learning fully at home, such as helping parents, playing games with friends, watching YouTube, accessing social media, and many other unproductive pieces of stuff leading to the minimum competence achievement. As time passes, most of them succeeded in managing their time and become accustomed to the ERT.

The findings highlighted findings found by the previous researchers. The results of a study conducted by [3] were in line with those of this study that not all participants shared the same experience as the others. Some students shared that they obtained positive educational experiences like better time management skills and enhanced skills of communication. However, some also struggle and perceived ERT as a negative experience since they were ack of communication and feedback and adjustment of workload. This condition might work differently depending on the respective instructors.

\subsection{Opportunities and Challenges}

The biggest challenge that the students face was their social and emotional conditions. Most of the time, they feel saturated and unmotivated when they joined ERT though the teachers have employed both synchronous and asynchronous modes. Some of them stated that they felt empty when they saw many of their friends turning off their cameras during the classroom and felt even worse when they conducted discussions with off-camera. Since they were easily got bored and unmotivated, their concentration did not work properly. Very often, during the classroom, they lost their concentration, got easily distracted by someone/something around them and sometimes, dozed off.

They mentioned that the teachers' techniques when teaching could help them raise their motivation to learn and reduce their being inattentive. When the teachers were communicative and implemented interesting media, strategies, and various activities, they became more enthusiastic to learn and could understand the materials. Motivating teachers were also exceptional and the most awaited ones since they felt enjoyed learning and emotionally and virtual-physically bound to one another.

These diverse responses were the basis for a deeper investigation of ERT. Besides challenges, the students admitted that they also gained advantages. In the situation where a face to face learning was hard to implement, ERT is one of the best alternatives as they could still experience learning and make the most of the use of technology to support their learning. Imagining no available adaptable technology during this crisis was one of the most frightful things to experience. Besides formal learning in the classroom, the ERT provided them plentiful opportunities to attend classes without breaking the health protocols and achieve the minimum targeted competencies. It is in line with the findings of a study conducted by [12] that a shift of instruction is needed during emergencies, such as blended learning (especially imporium type of blended learning, which is fully conducted online with synchronous and asynchronous modes). The roles of policymakers at the campus are also crucial to conduct regular evaluation toward the implementation of ERT so that students can be well fostered, though, not as much as when they have the faceto-face classroom.

The finding of this study revealed that there are two opposing views about ERT in the realm of language teaching and learning, positive and negative. At the beginning of its implementation, negative views outnumbered positive ones. However, as time passes, more adaptations were done and more students perceived ERT positively as it fosters their learning and achievement. As this study is limited to the context of vocational higher education and the participants were not large in the form of number, further studies with a bigger number of samples were suggested.

\section{CONCLUSION}

The results of this study concluded that students' perception toward ERT changed over time, from mainly negative into mostly positive. At the beginning of the survey, most responses were negative since they still struggled with the situation and could not find the best pattern to cope with the situation. On the contrary, they became more elated and perceived positively when they were asked the same questions a year later, showing that they could find the effectiveness of ERT in fostering their learning. Based on the results of this study, an improved and effective emergency remote teaching system that maintains academic and non-academic achievement and is similar to traditional classroom teaching can be designed and teachers can find more various techniques and activities to facilitate the students to learn and promote their academic success.

\section{AUTHORS' CONTRIBUTIONS}

The first author designed, directed the project, and developed the theoretical formalism. In addition, the first, second, and third authors collected, coded, and analyzed the data, and wrote the manuscript.

\section{ACKNOWLEDGMENT}

This publication was supported by Grant Number SP. 337/PL17.4/PG/2021 Date 2 June 2021 from DIPA Politeknik Negeri Jember. Its contents are solely the 
responsibility of the authors and do not necessarily represent the official views of Politeknik Negeri Jember.

\section{REFERENCES}

[1] C. B. Hodges, S. Moore, B. B. Lockee, T. Trust, M. A. Bond, The difference between emergency remote teaching and online learning, 2020.

[2] N. Johnson, G. Veletsianos, J. Seaman, U.S. Faculty and Administrators' Experiences and Approaches in the Early Weeks of the COVID-19 Pandemic, Online Learning 24: 2, 2020, pp. 6-21, doi:10.24059/olj.v24i2.2285.

[3] M. Shin, K. Hickey, Needs a little TLC: Examining college students' emergency remote teaching and learning experiences during COVID-19. Journal of Further and Higher Education, 45 (7), 2021, pp. 973986.

[4] F. M. Amin, H. Sundari, EFL students' preferences on digital platforms during emergency remote teaching: Video Conference, LMS, or Messenger Application?, Studies in English Language and Education, 7 (2), 2020, pp. 362-378.

[5] E. Aguliera, B. Nightengale-Lee, Emergency remote teaching across urban and rural contexts: perspectives on educational equity, Information and Learning Sciences, 2020.

[6] M. W. Alexander, A. D. Truell, J. J. Zhao SExpected advantages and disadvantages of online learning: Perceptions from college students who have not taken online courses. Issues in Information Systems, 13(2), 2012, pp. 193-200.

[7] A. D. Dumford, A. L. Miller, Online learning in higher education: Exploring advantages and disadvantages for engagement. Journal of Computing in Higher Education, 30(3), 2018, pp. 452-465.

[8] D. Tiene, Online discussions: A survey of advantages and disadvantages compared to face-toface discussions. Journal of Educational Multimedia and Hypermedia, 9(4), 2000, pp. 369-382.

[9] T. E. Shim, S. Y. Lee, 2020 College students' experience of emergency remote teaching due to COVID-19. Children and youth services review, 119, 2020, 105578.

[10] A. Saykili, Distance education: Definitions, generations, key concepts, and future directions. International Journal of Contemporary Educational Research, 5(1), 2018, 2-17.
[11] A. H. Miqawati, Pronunciation Learning, Participation, And Attitude Enhancement Through Mobile Assisted Language Learning (Mall). English Review: Journal of English Education, 8(2), 2020, pp. 211-218.

[12] A. H. Miqawati, F. Wijayanti, Blended Learning: Revealing Its Transformative Potential and Practice During the Covid-19 Era. In The First International Conference on Social Science, Humanity, and Public Health (ICOSHIP 2020), 2021, pp. 175-177. Atlantis Press. 